\title{
Robotics for Supply Chain and Manufacturing Industries and Future It Holds!
}

\author{
Virbahu Nandishwar Jain \\ Industry Research Analyst (MIE, CE, CPIM) \\ Hanover, NH, USA
}

\begin{abstract}
How Can Humans adapt to a Life with Robots with ease?

All historical events have briefed humans that the new technologies come along, most people are slow to adapt, taking time to become familiar and comfortable with the new tools and their impacts and applications. The problem that arises with AI and robotics is that these resources are growing exponentially, making it all much more important to discuss their impact and evolutionary needs now. Are we prepared to adapt for a future in which we live and work with robots regularly? While there is no absolute, perfect answer to this question, one very important thing to keep in mind is that the purpose of robotic aides is to improve our lives in a measurable way. We need more education and conversation about the roles of robots in our society. We must address issues like how their roles will evolve as they become more popular and lifelike, what their relationships will be to humans, and how the roles of humans may change as a result. We must engage in these forums where these points could be sorted out. If we are not properly prepared in advance, then a sudden influx of these robots could lead to social unrest, including a lot of confusion. Can we wait till the time these BOTS are in market and in our daily lives, yes if we are ignorant about it now. International laws and restrictions can play a key role in how robots are created and used within the next few years and these laws can prohibit people from causing harm as well in a more meaningful way that human could understand. This paper will talk about how the Robots are changing our day to day lives and how Supply Chain is impacted with the induction of Robotics and the areas where Robots have played a huge role and in future what are the aspects of Robots.
\end{abstract}

Keywords - Artificial Intelligence, Machine Learning, Supply Chain, Manufacturing, Data, AI Pattern, Data Science, Algorithms, Use Cases, Industry Revolution 4.0

\section{INTRODUCTION}

Many movies have depicted robots in a negative light, which in turn has negatively affected many people's impressions about robots. However, in reality, robots and automated machines have a little in common with those scary creatures we see on the silver screen. Real life robots, which are extremely complex, were basically created to help with tasks that are too dangerous or difficult for humans and are predominantly used for good rather than evil [3].

Essentially, a robot is any machine that can be programmed to carry out complex actions. The word robot stems from the Slavic word robota [1][30], which means forced laborer.

The idea of an intelligent machine has been around since ancient times, with many myths promoting the idea of an artificial human. Many religions feature such characters in their tales.
The first electronic autonomous robots (or "modern-day" robots) were created in Bristol, England in 1948 by William Grey Walter [1].

There is general agreement that for a machine to be defined as a robot by today's standards, it needs to meet the following criteria:

- Can be electronically programmed.

- Can process data or physical perceptions.

- Can work autonomously.

- Can move around.

- Can operate some of its physical parts or a process.

- Can sense, and change according to, its environment.

- Can show intelligent behavior similar to a human being.

Today's robots are most commonly used for industrial tasks such as manufacturing, but they are becoming more and more commonplace for other purposes (e.g., medical operating robots, dog therapy robots). They are also increasingly being utilized for tasks that are too dangerous for humans, such as the use of drones in military situations [3].

Since robots were originally created purely for entertainment purposes, many of the early ones were developed to look like animals or humans. However, during the Industrial Revolution these automated machines began to be used for more practical reasons, for which they no longer needed to look human. Today, robots have come a long way in both aspects (their abilities to look like humans or animals and their practical capabilities). As a result, there is an enormous variety of robots with different combinations of functions and physical appearances. Over the last few decades, many types of robots have returned to being designed to increasingly look and act more like humans, but they have not yet reached the complexity where they can make their own decisions without preprograming [3].

Today one of the most widely recognized robots is the Roomba, a small, circular vacuum cleaner that can adjust to its environment through built-in sensors. Over 14 million Roombas have been sold, according to the CEO of iRobot, the company that makes the Roomba [2]. Roomba works at vacuuming a room based on preprogrammed modes including spot mode, max mode and dock mode. Each mode instructs the machine to perform a specific task in a specific way. For example, spot cleaning mode causes the Roomba to clean a small area by working in an outward-then-inward spiral motion. Roomba is also preprogrammed with "reactions" to bumping into objects, which causes it to reverse and change paths [3].

Despite how robots are portrayed in movies, there are many types and styles of automated machines, from factory 
robots to companion ones, all of which are designed to be helpful to humans [3].

\section{A. Where these Robots come from?}

Robots have become commonplace in many industries. In fact, the number of robots being ordered and shipped has dramatically increased over the last few years.

The Robotics Industries Association (RIA) has announced record-breaking sales of robots in early 2017, with nearly 10,000 robots ordered in North America alone. Those orders were worth $\$ 516$ million for the robotics industry. The statistics show a 32 percent increase over the first quarter of 2016 [2]

Shipments of robots have also increased, with over 8,000 being sent to North American companies in the first few months of 2017. That is a 24 percent increase over the first quarter of 2016. The majority of the robots ordered in early 2017 (53 percent) were for use in the automotive industry. Robot orders for use in other industries, including metals, semiconductors, electronics, food, and consumer goods, were also behind the boost for the robotics industry.

There are now about 250,000 robots being used in various industries in North America, according to the RIA[3]. It has been estimated that there will be over 1.4 million new robots being sent to factories around the world by 2019 [4].

Currently the European Union and China are leading the way with 65 percent of EU countries having a high average of industrial robots per 10,000 employees. However, China is expected to reach 40 percent of the market volume of industrial robots by 2019 [3].

Joe Gemma, President of the International Federation of Robotics, was quoted as saying,

"Automation is a central competitive factor for traditional manufacturing groups but is also becoming increasingly important for small and medium-sized enterprises around the world." [4]

The Federation estimates that 2.6 million industrial robots will be deployed by 2019 . According to statistics, 70 percent of all robots are currently being used in the automotive, electronic, and metal or machinery industries. [4] The robotics industry saw a record-breaking year in 2015, with 254,000 units sold globally.

\section{B. Types of Robots}

There are many different varieties of robots that have been designed for use in the metal, electronic and automotive industries, but those are certainly not the only types of robots that have been created. There are a multitude of sizes, shapes and styles of robots that are used for a wide array of reasons around the world [3].

For example, the medical industry has been using robots for numerous purposes including surgery, guided vehicles and lifting aides. Robots have also been designed to help out at home. From vacuum cleaners to lawnmowers, there are robots that have been created to perform various domestic chores. There are also military robots that help with tasks such as bomb disposal and transportation, as well as robots for use in law enforcement environments. In addition, robots have been designed for children's entertainment, such as toy dinosaurs, for hobby/competition purposes, and for space exploration, such as the Mars Rovers.
In addition to their many purposes, robots also come in a variety of shapes, sizes and mobility capabilities. There are:

- Stationary robots, which can include robotic arms with limited movement.

- Wheeled robots.

- Legged robots.

- Flying robots.

- Swimming robots.

Some of the more fascinating robots are the ones that are human-shaped that have been designed as companions.

One such robot, named Pepper [5], has been created to recognize human emotions. This robot has been used in some stores in Japan and is considered a domestic companion. Pepper has been programmed to recognize emotions based on facial expressions, body movements and words spoken. The robot then selects a behavior to react to the emotion it recognizes.

As technology advances, so does the field of robotics, leading to a vast array of sizes, shapes and types of automated machines - or robots. From assembling cars to assisting customers in stores, robots have been designed and programmed to perform tasks in many different industries including manufacturing, the military, medicine and retail, just to name a few [3].

\section{Global Robotics Wars}

Many countries have large numbers of working robots, and studies have shown that those countries with the most robots have lower unemployment rates than other countries.

In 2016 Japan was considered to be the country with the most operational robots, according to research done by Bank of America and Merrill Lynch. At the time the country had 310,508 robots[3]. The United States came in second place with 168,623 operational robots, while Germany took third place with 161,988 .

Recently, South Korea was documented as having the highest density of robots than any other country in the world, according to one media outlet. [6] In addition, the government of South Korea announced that over the next five years it will invest $\$ 450$ million into the robotics industry.

In 2016 the International Federation of Robotics published a report which included some interesting statistics on the number of robots per 100 workers in different countries. South Korea was number one with 5.31 robots per 100 workers, while the global average was only 0.69 robots per 100 workers [4].

\section{ROBOT-TO-WORKER RATIOS ARE GROWING WORLDWIDE}

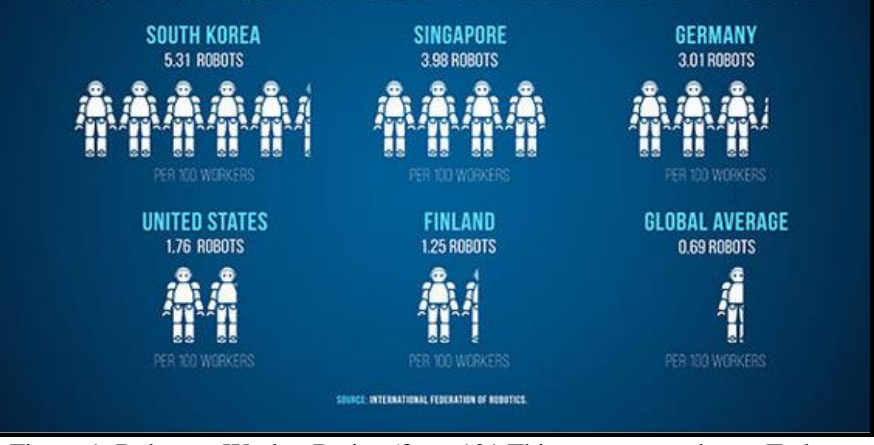

Figure 1: Robot-to-Worker Ratios (from 101 Things you must know Today about our future, 2018) 
In one study researchers found a link between robotics and economic growth. They concluded that 10 percent of GDP growth and 16 percent of productivity improvements were linked to the number of robots in a country [7].

While there has been speculation that automation brings higher rates of unemployment, that has not always proven to be true. One economic

In one study researchers found a link between robotics and economic growth. They concluded that 10 percent of GDP growth and 16 percent of productivity improvements were linked to the number of robots in a country [7].

While there has been speculation that automation brings higher rates of unemployment, that has not always proven to

\section{USE CASES FOR ROBOTICS- HOME}

This section gives an outlook into the near future of blockchain technology for Supply Chain Space, by discussing the information and partly differing opinions received from several leading researchers and industry experts. It is rumored that the first successful use cases will be implemented and publicly announced within the next three to five years. As already shown above, the time to market differs significantly among the potential areas, caused by different technical requirements of the specific solution. Whereas many see the first more extensive implementations in the financial sector, other industries are catching up rapidly with their development. A good example is the energy sector, where promising PoCs, namely the cooperation project of Siemens [3].

In the future, your home will probably be full of different types of robots performing various tasks that you prefer not to do. There will likely be robots anywhere from your kitchen to your living room to your garden doing things that will help you to automate and save time. By saving us time, robots will help enable humans to focus on the things we enjoy doing, rather than filling up our days with the mundane tasks and chores we must do. Following are some of the most common types of robots that are currently being developed, and some that have already reached the market. Keep in mind, however, that in the future there will be many more advanced versions of these robots.

- Kitchen Robots: One of the most interesting types of kitchen robots currently under development is a cooking one by Moley, which can reportedly prepare over 100 meals by top chefs including Thomas Keller, Alain Ducasse and Gordon Ramsay. This robotic kitchen comes with cabinetry, appliances and two robotic motion capture systems, as well as other features that allow this automated chef to cook sophisticated meals. The company has also been working on a feature that would add a dishwashing and kitchen cleaning element to this product. Moley's robotic kitchen will reportedly be available by 2018 and cost about $\$ 15,000$. It is quite likely that future homes will be sold with robotic kitchens already installed [8].

- Cleaning Robots: The most familiar cleaning robot is the Roomba by iRobot. The company is considered an be true. One economic publication notes that 9 to 12 million new jobs were created by the robotics industry between 2000 and 2016\{193\}, arguing that those countries with higher numbers of robots are also the countries with lower unemployment rates. The theory behind this is that although robots may replace labor-intensive jobs, they also create new ones in the technology field for robot designers, manufacturers, programmers, and the like. While Asian countries tend to have higher numbers of working robots, western countries like the United States are not so far behind. It is also clear that the robotics industry will continue to grow in the coming years, as will the creative jobs market along with it [3].

industry leader because it was the first one in this market, with the Roomba robotic vacuum cleaner. iRobot was founded in 1990 and first released the Roomba in 2002, according to its website [9]. The company now sells several home cleaning robotic models, including the Braava jet mopping robot, all of which it is constantly working on improving. iRobot has been developing a variety of other home robotic products as well. Today there are other companies moving into this space as well, such as bObsweep, ILIFE and ECOVACS Robotics, all of which have developed floor cleaning robots.

- Ironing Robots: Ironing robots promise to be huge time savers, as ironing can be a big headache for busy people. The first ironing robot was the Dressman from Siemans, which will prove to be a valuable utility for those looking to save time [10]. This machine, which is in the shape of an upper torso, works by using hot air on a damp shirt. The shirt is placed on the robot and the hot air inflates and dries it while removing creases at the same time.

- Gardening Robots: An innovative robot, called the Tertill, can assist with maintaining a garden by weeding it for you [11]. It can move around your garden, measure the size of every plant, and cut all of those that are less than an inch long. It also has a way to protect your smaller, growing plants from being cut. Also, because the Tertill is solar powered, it can stay right in the garden itself, allowing it to work the ground daily. The Tertill was designed by one of the team members that also worked on the Roomba.

- Lawnmowing Robots: There are several companies that have already produced robotic lawnmowers, including Gardena and Husqvarna, among others. However, the current versions of these robots have only received average consumer ratings at online stores such as Amazon.com. As with other types of robots, the lawnmower robot will only improve with time [3].

- Basic Home Robots: This type of robot is more of a companion style and many have been designed to recognize human expressions and emotions. Because there are so many companies currently working in this space, there will be a wide variety of home robots on the market in the future. An example of one such companion robot is Kuri, which was developed by 
Mayfield Robotics, a company based in California. Like Kuri, many of the home companion robots are still in the early days of design and thus are rudimentary compared to what we can expect in the future. The home companion robots of the future will likely be equipped to learn about the home and family members, record videos, and help out in a variety of ways [12]

- Smart Home Robots: In the future, everything in our homes will be connected through the Internet of Things (IoT). It will be commonplace to have robots, and everything will be connected. This will include all the home items like the consumer ratings at online stores such as Amazon.com. As with other types of robots, the lawnmower robot will only improve with time [3].

- $\quad$ Basic Home Robots: This type of robot is more of a companion style and many have been designed to recognize human expressions and emotions. Because there are so many companies currently working in this space, there will be a wide variety of home robots on the market in the future. An example of one such companion robot is Kuri, which was developed by Mayfield Robotics, a company based in California. Like Kuri, many of the home companion robots are still in the early days of design and thus are rudimentary compared to what we can expect in the future. The home companion robots of the future will likely be equipped to learn about the home and family members, record videos, and help out in a variety of ways [12].

- Smart Home Robots: In the future, everything in our homes will be connected through the Internet of Things (IoT). It will be commonplace to have robots, and everything will be connected. This will include all the home items like the refrigerator and other appliances and may even extend to other home items like furniture. Home robots will also be commonplace in the future, and these will be connected to the IoT as well [3].

The creator of the Roomba believes that in the future all robots will be invisible.

"Consumers want a spotless floor; not a machine buzzing around underfoot," Joe Jones wrote in a blog post[13]. "People want the things a robot can do for them; the robot itself may just get in the way."

The positive side of home robotics and smart homes will be that the robots can automate mundane tasks and help us save time. They will allow people to stop doing many of the chores they dislike, leaving them more time to do what they enjoy [3].

However, a possible negative effect could be that people may start to lose the ability to engage and interact with other human beings due to spending too much time with robots in their homes. We must keep in mind that the basic idea of having robots is to help us with tasks, not to change who we are as human beings[3].

Another concern regarding home robots is the possible loss of privacy. Most home robots will be connected to the cloud and might also be capable of recording private conversations and other personal information within the home. Knowing that their privacy could potentially be violated will make many people feel nervous about allowing these robots into their homes. This apprehension will likely cause consumers to adapt to home robots at a slower pace, which in turn will slow down the growth of home robots in general[3].

The increasing variety, size range, and capabilities of robots have driven market growth.

Growth of robots on the market

Base quantity SKUs

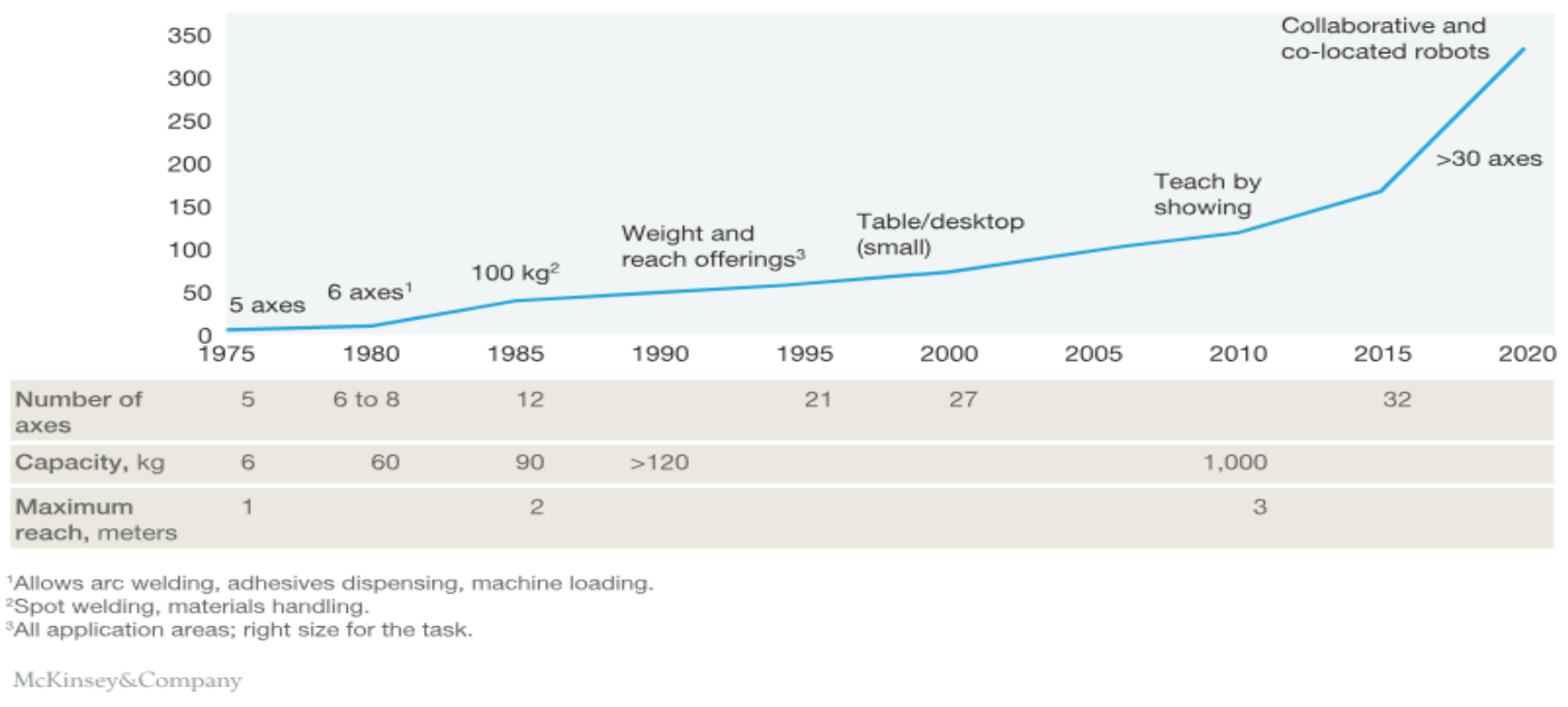

Fig 2 : Robot on new Roles (Source: Mckinsey, 2018) 


\section{USE CASES FOR ROBOTICS- RPA}

Robotics Process Automation(RPA) allows organizations to automate task just like a human being was doing them across application and systems. Robotic automation interacts with the existing IT architecture with no complex system integration required[29].

RPA can be used to automate workflow, infrastructure, back office process which are labor intensive. These software bots can interact with an in-house application, website, user portal, etc. The RPA is a software program which runs on an end user's pc, laptop or mobile device. It is a sequence of commands which are executed by Bots under some defined set of business rules. The main goal of Robotics process automation process to replace repetitive and boring clerical task performed by humans, with a virtual workforce. RPA does not require the development of code, nor does it require direct access to the code or database of the applications[29].

Robotic Process Automation (RPA) is still in its infancy in supply chain operations, however, organizations have accelerated towards including automation in their supply chains to make them lean and efficient. Companies across industries such as healthcare, retail, and manufacturing have traditionally relied on technologies such as RFID (Radio Frequency Identification), ERP (Enterprise Resource Planning), CRM (Customer Relationship Management), etc.

In the beginning phases of RPA in Supply Chain, software robots were not flexible enough to handle the complex scenarios that sometimes sprung up as they were unintelligent and could only automate parts of the supply chain that were straightforward and followed a set pattern. For anything else, manual intervention was critical. Fast forward to today, the inclusion of intelligent bots with machine learning capabilities and cognitive abilities has led us to make RPA systems resemble humans to an extent. With these technologies in view, we are moving towards automating tasks that are defined by business rules and pave instructions for processing inputs.

\section{A. RPA Implementation Methodology}

- Planning: In this phase, you need to Identify processes which you want to automate. Following checklist will help you identify the correct process

- Is the process manual \& repetitive?

- Is the process Rule-based?

- Is the input data being in electronic format and is readable?

- Can existing System be used as it is with no change?

- Next, steps in planning phase are

- Setup project team finalize implementation timelines and approach.

- Agree on solution design for performing RPA processes.
- Identify logging mechanism that should be implemented to find issues with running bots.

- Clear roadmap should be defined to scale up RPA implementation

- Development: In this phase, you start developing the automation workflows as per agreed plan. Being wizard driven, the implementation is quick

- Testing: In this phase, you run Testing cycles for inscope automation to identify and correct defects

- Support \& Maintenance: Provide continuous support after going live and helps in immediate defect resolution. Follow general maintenance guidelines with roles and responsibilities with business and IT support teams[29].

- Best Practices of RPA Implementation

- One should consider business impact before opting for RPA process

- Define and focus on the desired ROI

- Focus on targeting larger groups and automating large, impactful processes

- Combine attended and unattended RPA

- Poor design, change management can wreak havoc

- Don't forget the impact on people

- Governance of the project is foremost thing in RPA process. Policy, Corporate, Government compliance should be ensured[29].

\section{B. General Use of RPA}

- Emulates Human Action: Emulates human execution of the repetitive process using various application and systems.

- Conduct high-volume repeated tasks: Robotics process automation can easily simulate rekeying of data from one system to another. It performs tasks like data entry, copying, and pasting.

- Perform Multiple Tasks: Operates multiple and complex tasks across multiple systems. This helps to process transactions, manipulate data and send reports.

- Virtual' system integration: This automation system can transfer data between disparate and legacy systems by connecting them at the user interface level instead of developing new data infrastructure.

- Automated report generation: Automates the extraction of data to comes up with accurate, effective and timely reports.

- Information validation and auditing: Resolves and cross-verify data between different systems to 
validate and check information to provide compliance and auditing outputs.

- Technical debt management: Helps to reduce technical debt by reducing the gap between systems, preventing the introduction of custom implementations.

- Product management: It helps to bridge the gap between IT systems and related product management platforms by automated updating of both systems.

- Quality Assurance: It can be beneficial to QA processes which cover regression testing and automating customer use case scenarios. INDUSTRY

\begin{tabular}{|c|c|}
\hline INDUSTRY & USAGE \\
\hline Healthcare & $\begin{array}{ll}\text { - } & \text { Patient registration } \\
\text { - } & \text { Billing }\end{array}$ \\
\hline HR & $\begin{array}{l}\text { - } \quad \text { New employee joining formalities } \\
\text { - } \quad \text { Payroll process } \\
\text { - Hiring shortlisted candidates }\end{array}$ \\
\hline INSURANCE & $\begin{array}{ll}- & \text { Claims Processing \& Clearance } \\
\text { - } & \text { Premium Information }\end{array}$ \\
\hline MANUFACTURING \& RETAIL & $\begin{array}{ll}\text { - } & \text { Bills of material } \\
\text { - } & \text { Calculation of Sales }\end{array}$ \\
\hline TeleCom & $\begin{array}{ll}\text { - } & \text { Service Order Management } \\
\text { - } & \text { Quality Reporting }\end{array}$ \\
\hline TRAVEL \& Logistic & $\begin{array}{ll}\text { - } & \text { Ticket booking } \\
\text { - } & \text { Passenger Details } \\
\text { - } & \text { Accounting }\end{array}$ \\
\hline Banking and Financial SERVICES & $\begin{array}{ll}\text { - } & \text { Cards activation } \\
\text { - } & \text { Frauds claims } \\
\text { - } & \text { Discovery } \\
\end{array}$ \\
\hline GOVERNMENT & $\begin{array}{ll}\text { - } & \text { Change of Address } \\
\text { - } & \text { License Renewal }\end{array}$ \\
\hline INFRASTRUCTURE & $\begin{array}{l}\text { - } \quad \text { Issues Processing } \\
\text { - } \quad \text { Account setup and communication }\end{array}$ \\
\hline
\end{tabular}

Table 1: Applications of RPA (Source: Guru99)

At the higher level, RPA in Supply Chain can be used to predict outcomes and support complex decision making, thereby, helping employees with more than just robotic tasks. Here are a few areas in the supply chain domain that are ready to change with RPA[24].

- $\quad$ Order Processing and Payments: The order placement and processing part of a supply chain essentially consists of three phases-

$$
\begin{array}{ll}
\circ & \text { Product selection } \\
\circ & \text { Payment processing } \\
\circ & \text { Order placement confirmation }
\end{array}
$$

- There are still businesses within a set of industries today that rely on old manual paperwork to process transactions which can be entirely digitized. Order processing and payments can be automated such that information can be directly ingested into the company database, payment gateways can process the desired amount, and a software solution can send out email and text message confirmations for the placement of order. As on today, with the advent on AI, multiple insurance companies rely on bots to automate claims processing as well \& by automating this back-office work, organizations can ensure their employees focus on quality tasks that require human intelligence. To optimize productivity and create a smooth supply
- Data migration: Allows automated data migration through systems which is not possible using traditional mediums, like document, spreadsheets or other source data files.

- Gap solutions: Robotic automatic fills the gaps with process deficiencies. It includes may simple tasks as password resets, the system resets, etc.

- Revenue forecasting: Automatically updating financial statements to predict revenue forecasting[29]. 
products and spares to meet demands. RPA can make inventory management easier by keeping a tab on inventory levels, notifying managers when product stock levels are low, and automatically reordering products that go below a certain threshold level. Additionally, an RPA system can help predict the optimal inventory levels by taking into account the historical data and sketching out patterns in demand. RPA in Supply Chain would make the inventory management process efficient and always updated to accommodate spikes in demand. Enhanced insights from Robotic Process Automation in Supply Chain can lead to better decision making when it comes to restocking of inventory, thus resulting in cost optimization at all times reducing spares. As employees are freed of the monotonous task of maintaining records of inventory levels, they can focus on other mission critical areas of the supply chain.

- Vendor Selection: Vendor selection is usually an entirely manual process \& RPA aims to change that. At the ground level, a vendor selection process consists of several steps such as -

- Preparing a request for quotation

- Communications and discussions with vendors

- Analyzing vendor documents

- Evaluating the vendor and cross-checking their credits

$\circ \quad$ Finalizing the vendor

- When RPA in Supply Chain is implemented, all of these tasks can be made more efficient, productive, and automatic. Human intervention, then, is only required to carry out the initial phases of specifying the project, generating a list of vendors, and engaging in face-to-face negotiations. Apart from these instances, humans will not need to intervene in the vendor selection process once RPA implementation is completed for an enterprise.

- Shipment Status Communication: Most businesses regularly receive shipment status inquiries from customers. The manual process looks like this- an employee would personally open each email, address the query by making a note of the shipment and then looking it up in the ERP software to reply back to the customer with the exact shipment status. However, with the introduction of RPA in this case, the complete process right from- opening the email, making sense of what the customer needs, logging into the ERP system, to communicating the exact status to the customer- can be automated. In such a case, human intervention would only be necessary for some exceptional circumstances that are beyond the handling potential of a robot.

- Supply \& Demand Planning: Before automation, supply and demand planning wasn't exactly a cakewalk for the employees in any organization. They had to seek and gather the required data, combine the data and manage it in presentable formats, analyze exceptions to the data, and then communicate the plan. RPA in Supply Chain, with the help of Machine Learning and Artificial Intelligence, can enable organizations to predict demands and be prepared to cater to the unexpected spikes in demand. By automating a majority of tasks in the supply chain, organizations can now eliminate the possibility of manual errors and make operations efficient, selfdriven, and smart.

- To put things into perspective, it is wishful to think Robotic Process Automation can automate an entire supply chain at this stage. Because supply chain operations also include the front-desk operations, building and maintaining client relationships, and so on which goes on to show that human intervention still is needed to some extent in a supply chain[24].

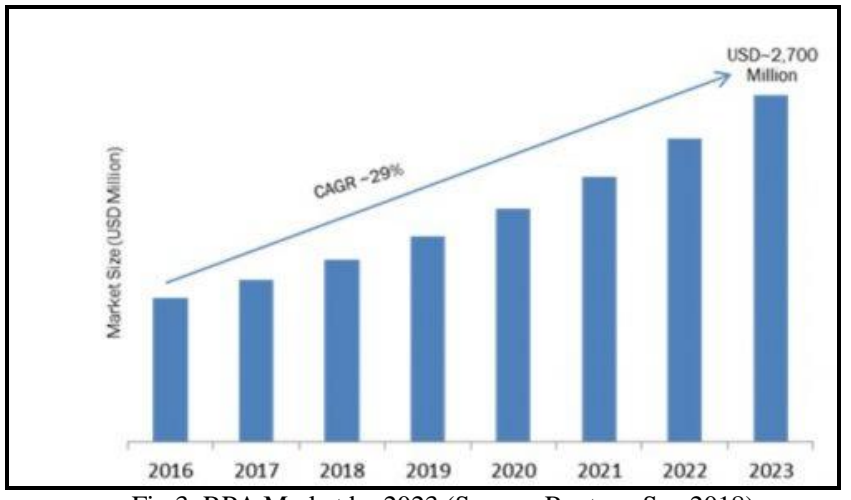

Fig 3: RPA Market by 2023 (Source: Reuters, Sep 2018)

\section{Benefits of RPA}

- Large numbers of the process can easily have automated.

- Cost are reduced significantly as the RPA takes care of repetitive task and saves precious time and resources.

- Programming skills are not needed to configure a software robot. Thus, any non-technical staff can set up a bot or even record their steps to automate the process.

- Robotic process automation support and allows all regular compliance process, with error-free auditing.

- The robotic software can rapidly model and deploy the automation process.

- The defects are tracked for each test case story and the sprint.

- $\quad$ Effective, seamless Build \& Release Management

- Real time visibility into bug/defect discovery

- There is no human business which means there is no need for time for the requirement of training.

- Software robots do not get tired. It increases which helps to increase the scalability.

\section{Disadvantages of RPA}

- The bot is limited to the speed of the application.

- Even small changes made in the automation application will need the robots to be reconfigured[29]. 


\section{INDUSTRY ROBOTICS LEADERSHIP}

- Boston Dynamics has emerged as the leading robotics company with the most advanced robots we have seen to date. The company got its start at the Massachusetts Institute of Technology (MIT) as a project with the objective of building robots that maneuvered like animals. The majority of Boston Dynamics' initial robot developments were funded by military contracts. That changed, however, when the company was bought by Google (Alphabet Inc.) in 2013 [14] and subsequently bought from Alphabet by SoftBank in June of 2017.

- The reason why Boston Dynamics is so significant is because it was the first company to create and showcase robots that are extremely sophisticated in design and agility. These robots have demonstrated the ability to perform complicated tasks that until now have only been seen in the movies.

- Thanks to social media sites such as YouTube and Facebook showcasing videos of their robotic creations, Boston Dynamics has been getting a great deal of attention. This attention has brought a whole new awareness to the public of what robots can really do and the wide range of possibilities robots provide for enriching our lives.

- Following are just three examples of the innovative robots Boston Dynamics has designed.

- Handle: The Handle model of robot is a biped that combines wheels and limbs, giving it lots of strength and mobility. The wheels allow the robot to move quickly on flat surfaces while the legs give it the ability to handle nearly any terrain. Handle can also make 4-foot jumps, adding to the already impressive 6.5-foot height of the machine [15]. The robot has 10 actuated joints, enabling it to lift heavy items and maneuver in all kinds of spaces. It can travel 15 miles on a full charge at a speed of 9 miles per hour and comes equipped with both electric and hydraulic actuators. Handle was first featured in a video at the 2015 DARPA Robotics Challenge. Wired magazine has called the robot an "evolutionary marvel. [16]"

- Spot: In keeping with its history of robotic animal creations, Boston Dynamics introduced Spot, a robotic dog intended to deliver packages, at the TED 2017 conference. This robot was designed by the company in an effort to find ways to commercialize its creations. Boston Dynamics has been getting Spot to practice delivering packages to employees' homes to help refine its abilities and design [14]. Spot has 12 joints, is electrically powered, and has hydraulic actuation. It has been designed to tackle both indoor and outdoor tasks and can run for 45 minutes on a single charge. Also, according to the company's website, by using its LIDAR and stereo vision, Spot can sense rough terrain [17].

- Spot Mini: A smaller version of Boston Dynamics' robot dog has been designed as a helpful worker in office, home, and outdoor environments. Spot Mini can carry up to 30 pounds, has 17 joints, and has the ability to climb stairs. Altogether Spot Mini weighs 25 pounds and can run for 90 minutes when fully charged. The Mini is more mobile than the larger version, and it comes with an arm that can be used to pick up and deliver objects. It also comes equipped with stereo cameras, depth cameras, and position/force sensors in the limbs that assist with navigation and mobility. In addition, the company claims that this is the quietest robot they have built [18].

Boston Dynamics CEO Marc Raibert has been quoted as saying that the company's long-range plans are to build robots for everyday use. "Our goal is really to build robots that are equal to or greater than people in terms of their mobility, manipulation dexterity, perception and intelligence," Raibert said [19]. Raibert also believes that robotics will be bigger than the Internet [20].

These robots are just a few examples of those that are being designed today, and there will be many, many more in the future. Because robots will soon be prevalent in the commercial space, now is the time to become more familiar with different types of robots and their capabilities for everyday life. Another company that has been in the media spotlight is Hanson Robotics, which has created an amazingly human-looking robot called Sophia.

Spot Mini has the ability to climb stairs. Altogether Spot Mini weighs 25 pounds and can run for 90 minutes when fully charged. The Mini is more mobile than the larger version, and it comes with an arm that can be used to pick up and deliver objects. It also comes equipped with stereo cameras, depth cameras, and position/force sensors in the limbs that assist with navigation and mobility. In addition, the company claims that this is the quietest robot they have built [17]

Boston Dynamics CEO Marc Raibert has been quoted as saying that the company's long-range plans are to build robots for everyday use. "Our goal is really to build robots that are equal to or greater than people in terms of their mobility, manipulation dexterity, perception and intelligence," Raibert said [19]. Raibert also believes that robotics will be bigger than the Internet [20].

These robots are just a few examples of those that are being designed today, and there will be many, many more in the future. Because robots will soon be prevalent in the commercial space, now is the time to become more familiar with different types of robots and their capabilities for everyday life.

Another company that has been in the media spotlight is Hanson Robotics, which has created an amazingly humanlooking robot called Sophia. According to the company's website, Sophia can do things like teach kids, help elderly people, and, most remarkably, even mimic human facial expressions [21].

In October of 2017, Saudi Arabia awarded an honorary citizenship to Sophia the robot, a move which was considered by many to be nothing more than a publicity stunt. This was widely believed because of the country's well-known ambition of transforming its oil-dependent economy into a more digitally-based one. Also, many experts agree that granting citizenship rights to an inanimate object like a robot could be problematic for several reasons [22] 


\section{ROBOTS ENABLING SUPPLY CHAIN}

This is accomplished similar to Angie's list where available services are tagged for search. The difference is that a properly designed supply network is a powerful B2B framework comprised of highly valued assets and capabilities. The providers of these assets and capabilities are able to subscribe to the network in a way where process robots can expose their availability through a set of contracting rules and pricing constructs. The advanced cloud platform which powers the robots also provides the process infrastructure so that not only can supply and demand be matched, but a transactional business infrastructure is made available in real time in order to conduct business. This is truly a market maker revolution. The innovation is that the platform is cloud based and layers across the existing ERP systems which have been deployed by various companies in the supply network. Otherwise it would be impossible access the assets or capabilities or even understand whether they were available for trade given the rigid structure of the existing ERP process flows. For the typical ERP system to develop the asset relationships and transactional process flows to support these types of opportunistic and adaptive trading relationships would take years rather than the real time environment supported by a many-to-many cloud platform.

And now think back to our original S\&OP problem that drove the need to develop a set of process robots in the example above. Having process robots work on our behalf to solve the problem, rather than through an outsourced contractor, makes the data available to share across the network[25].

The problem with traditional automation is that it creates islands of activity. Processes aren't intelligent or responsive enough to handle errors, changes in parameters, authorizations or any of the other issues that can arise at any time across the supply chain. When something goes wrong, the macro-driven process simply breaks and falls down.

On top of the error-prone macro-linked processes, human capital is needed to keep these 'islands' connected and running on a schedule.

In the diagram below, over 100 people are involved in linking the creation and review of plans - and changes to them where risks are identified. Without their involvement problems occur which can have huge consequences - on other stakeholders across the supply chain and on the organization itself when things go wrong.

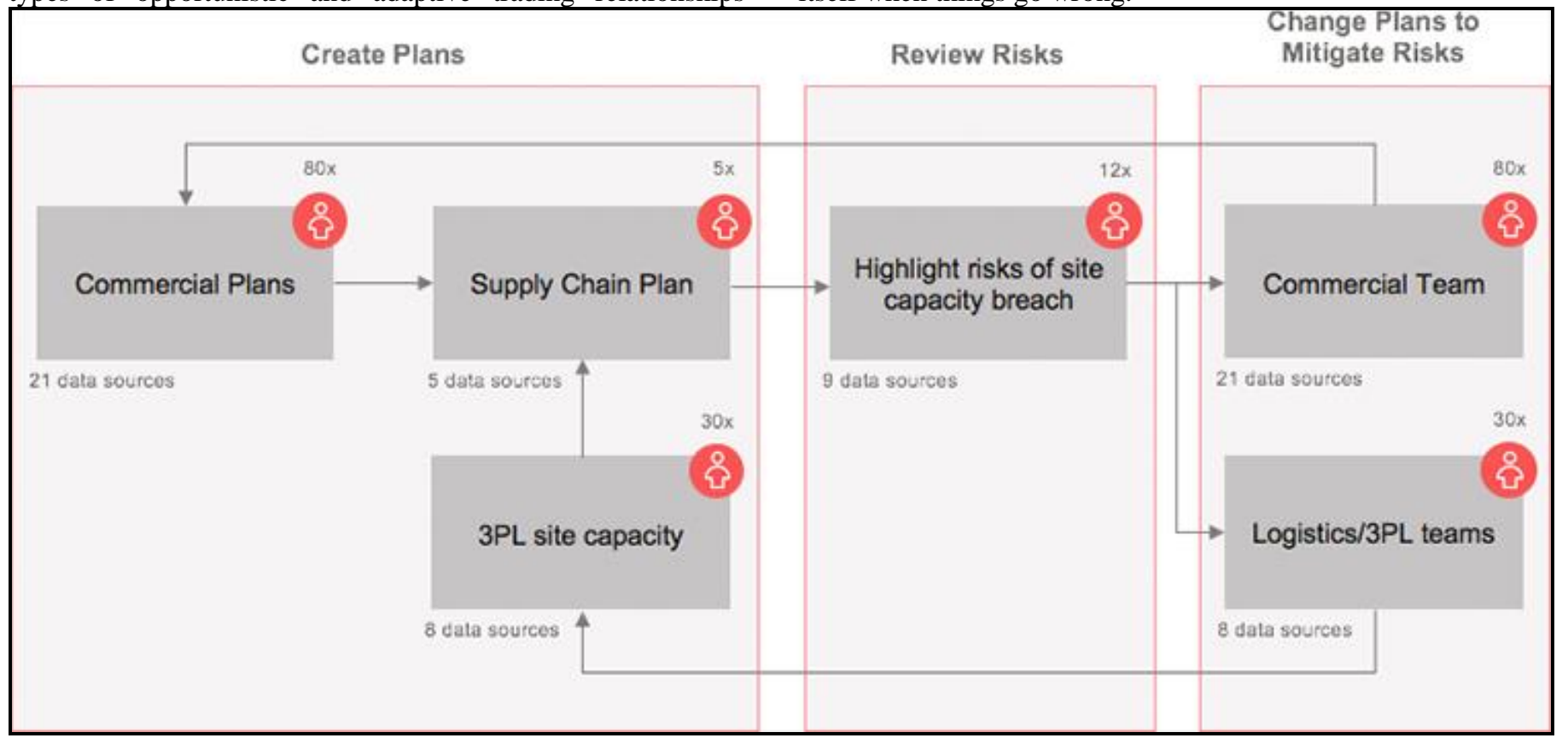

Fig.4: Linking and creation of plan in RRPA Supply Chain (Source: Redwood Software, 2017)

There is a better way. Robotics can deliver end-to-end visibility, control and automation across all these processes. The effects are reduced errors, more timely information and increased trust across the supply chain, both internally and externally. This is because suppliers and logistics companies know they can rely on the output of this process management.

Retail is an area where automation is put at the heart of the supply chain operation. And for obvious reasons: with short lead-times, disparate systems, a network of suppliers and multiple third-party logistics companies to coordinate, if an organization allows any of these to fail it isn't acceptable and can quickly increase costs, lose sales and damage trust in a brand.
It's no coincidence that Amazon - a master of supply chain management and digital process transformation renamed its then-recently-acquired automation unit as 'Amazon Robotics' as far back as 2012.

Looking at the 'traditional' automation example of banks of Excel spreadsheets managed by macros, large multichannel retailers can improve their supply chain planning capability. Superficially this is a gain, as it allows a level of automated activity without having to wait for IT to upgrade the ERP system. But on the downside, every single change to a process can have literally hundreds of ripple effects on people, systems and processes. In addition to these ripple effects, fragmented islands of automation also mean that plans must be created and reviewed to identify supply and demand 
conflicts across dozens of teams, systems and tools. Take this workflow: Updates on when stock will arrive at a port then prompt manual changes to planning and forecast systems, as well as other tools, throughout the supply chain. This has knock-on effects on the plans of suppliers and logistics providers. Of the several hundred risks that need to be reviewed, few involve complex decision-making. They could easily be automated by robotics. Without that end-to-end oversight, it's a process that doesn't scale and is full of potential pitfalls.

Those organizations that use robotics to take on repetitive, labor-intensive, logic-based processes also release their supply chain teams to focus on the higher-level strategic and decision-making aspects of the roles that are required to drive continual innovation and, ultimately, keep them motivated and happy at work[26].

\section{ETHICS AND ROBOTS}

There is no doubt that the fields of robotics and artificial intelligence will generate a lot of good things in the world. This can include faster research into serious illnesses and their cures, diminishing the number of fatalities in traffic accidents, and helping to stimulate economic growth, among other things[3].

In spite of this, there are still a number of fundamental ethical issues that arise with the use of robotic technologies. One basic premise that has been proposed by experts in the field for years is that the creation of robotic aides should always be done with an eye toward helping us to live better lives, promoting the welfare of mankind. There is no guarantee, however, that every individual or company that implements these technologies will adhere to this guideline. Furthermore, many are likely to encounter complex ethical issues in their search for economic gain using AI tools[3].

As you consider the ways in which robotic and AI technologies can be implemented, here are some of the ethical questions you should keep in mind:

- How Can We Ensure That Robotics Will Not Promote Inequality in the World? Because it's very likely that a small number of wealthy people will be the first to invest in robotics, it will be important to create initiatives to spread information and educational opportunities to all socioeconomic groups in regard to the benefits of AI-powered resources. How can this be accomplished?

- How Can We Preserve Social Skills as Interactions with Robotics Increase? Every time a new kind of technology becomes widely adopted, it changes the way people interact, not only with that tool, but also with each other. What are some of the ways we can encourage positive human relationships in the midst of AI technologies so that we don't lose essential communication skills?

- Should We Trust Robots Fully? Robotic tools are already being used in surgical centers and hospitals, the military, and other potentially life-or-death situations, a trend that is likely to grow. As the use of robotics continues to increase in other industries, and for serious purposes, how should we respond if $\mathrm{AI}$ tools fail to do what they are supposed to do, or even cause harm? What happens when people begin to doubt their own judgment, relying instead on robots to provide answers to important questions? One idea is to create an "ethical black box" to be embedded in all robots, which would allow them to explain their decision-making processes, an idea that I firmly agree with. You can read more about this suggestion here: https://goo.gl/SnCv2z

- What Rights Should Robots Have? While humans have basic intrinsic rights agreed upon and protected by most governments, what rights, if any, should intelligent robots have?

- How Do We Effectively Legislate the Use of Robots? As robotic technologies become less expensive and time-consuming to create, what kinds of legislative decisions will we need to make, as a society, to help us avoid making mistakes with dire consequences in the development and application of these tools?[3]

$\mathrm{AI}$ and robotic technologies and to encourage discussion on related topics. Another similar initiative, which is spearheaded by Reid Hoffman, founder of the Omidyar Network, the Knight Foundation and LinkedIn, is called the Ethics and Governance of Artificial Intelligence Fund. Currently, however, these initiatives are not widely known, so many people aren't aware of the speed at which robotics are developing and how important it is for individuals, businesses, and even governments to start thinking and talking about the impacts of robotic technologies right now[3].

\section{CHALLENGES IN RPA IMPLEMENTATION FOR SUPPLY CHAINS}

According to a report published by Deloitte, there are still quite many challenges organizations face when they begin to strategize RPA or go at it for the first time.

Here are the top 5 challenges the report highlights -

- Process Standardization - Complex processes lead to complexity in the robot. At all stages of the RPA journey, organizations face process standardization as a critical challenge. Complexity in processes hike the costs of implementing RPA while increasing operating costs and business disruption. Organizations, unfortunately, realize that where proper documentation exists, even in those places, the processes are not always well understood.

- IT Support - The support and consultancy of an IT organization are vital while strategizing RPA in supply chain. It is essential and advisable to include an IT organization throughout the RPA implementation process.

- The Flexibility of Solution - RPA, at the outset, used to be considered a stagnant automation process. It carried a notion that robots will only learn once and that they need to be taught perfect lessons for them to perform later. Thanks to Artificial Intelligence and Machine Learning, solution flexibility can now be added to all stages of automation, though agility is perceived as a challenge. 
- $\quad$ Stakeholder Expectations - Stakeholders have now started warming up to RPA, but it is a significant challenge to move RPA in Supply Chain up the priority ladder, and make sure it does not amount to complete disruption.

- Employee Engagement - Organizations that have succeeded in scaling RPA had first engaged their employees and built buy-in to change processes orgwide. Though things vary across organizations, there is a need for enterprises to take steps so that employees accept RPA with minimal resistance[24].

\section{INDUSTRY EXPERTS THOUGHT PROCESS AND} FUTURE FORECAST

This section provides feedback from leading research organizations for Robotics and how they will be represented in the near future.

IDC forecasts that by 2021, 20 percent of the largest (G2000) manufacturers will depend on a secure backbone of embedded intelligence to automate large-scale processes and speed execution times by up to $25 \%$. This backbone will use IoT, Robotics, blockchain and cognitive (artificial intelligence and machine learning).

\section{Hype Cycle for Emerging Technologies, 2018}

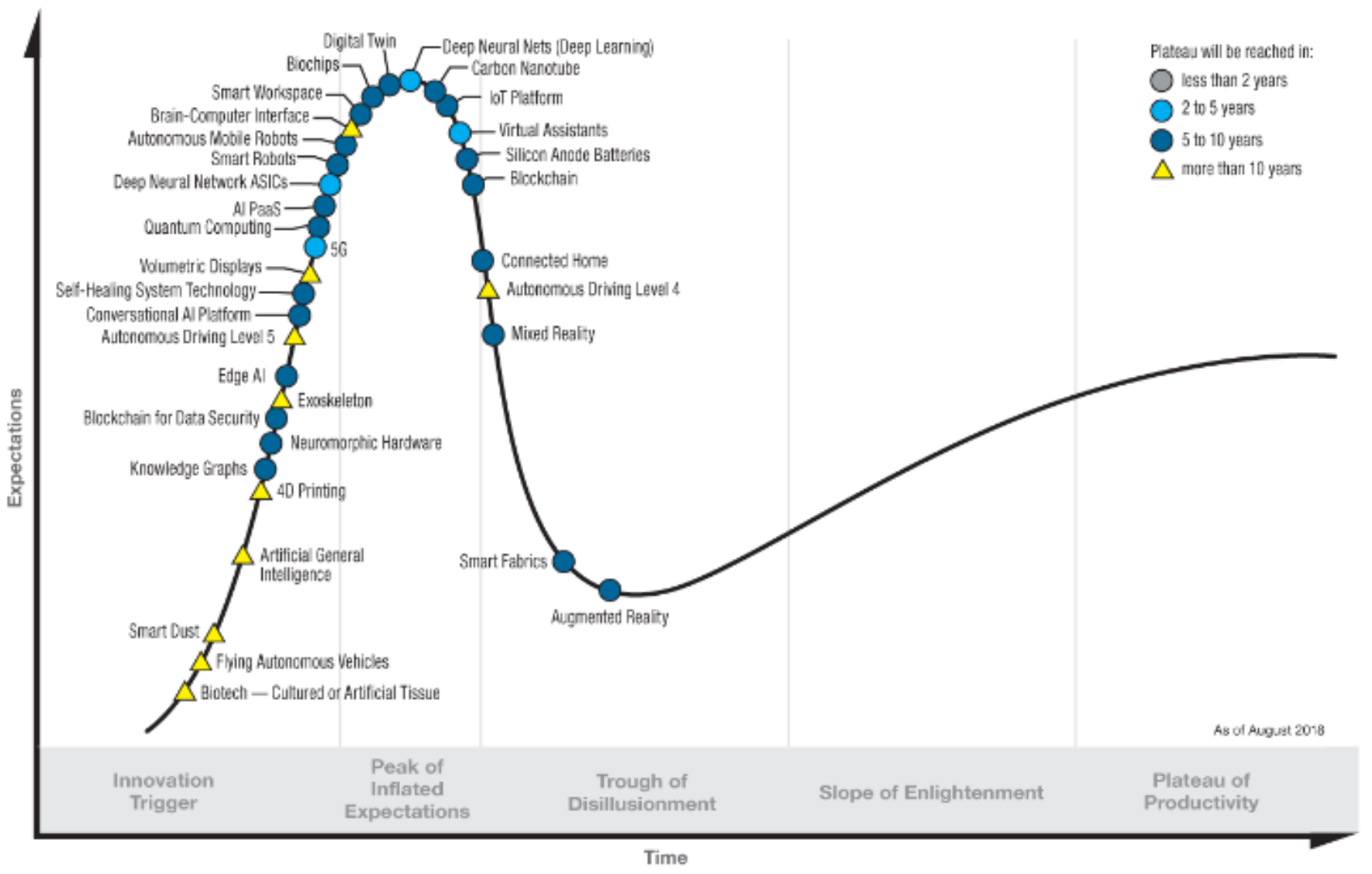

\section{gartner.com/SmarterWithGartner}

Figure 5: Hype Cycle for emerging technologies, Source: Gartner (from August 2018)

IDC expects that by 2018 (!) 30 percent of all new robotic deployments will concern smart cobots that operate three times faster than current robots (with 'current' being end 2016) and are safe for work around humans. E-commerce, as mentioned plays an important role. As IDC says in the same press release in its worldwide robotics predictions: "By 2018, $45 \%$ of the 200 leading global ecommerce and omni-channel commerce companies will deploy robotics systems in their order fulfilment warehousing and delivery operations"'[23].
Tractica market intelligence firm forecasts that worldwide warehousing and logistics robot unit shipments will increase from 40,000 in 2016 to 620,000 units annually by 2021 . The market intelligence firm estimates that global market revenue for the sector reached $\$ 1.9$ billion in 2016 and anticipates that the market will continue to grow rapidly over the next several years, reaching a market value of $\$ 22.4$ billion by the end of 2021. 


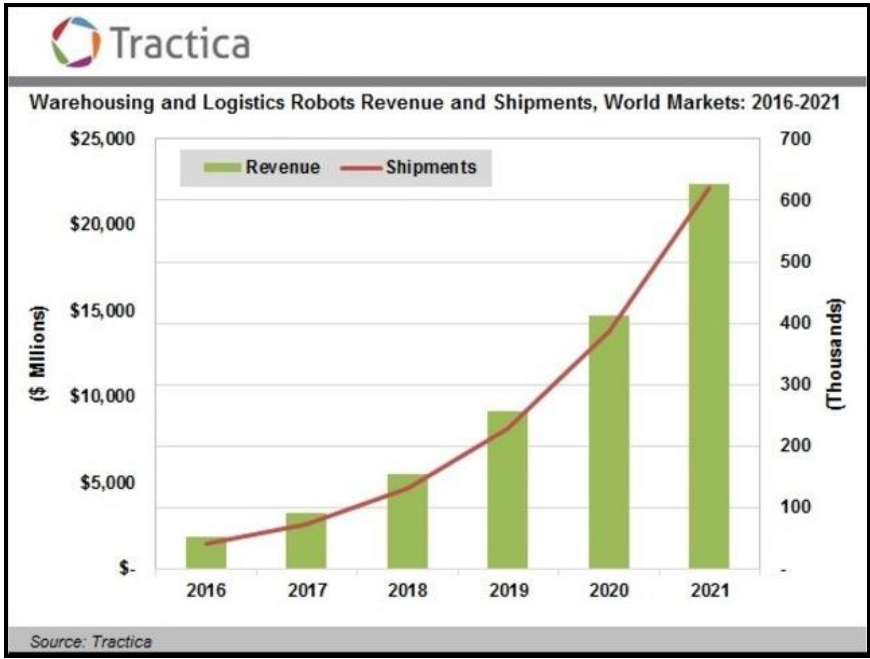

Fig. 6: warehousing and logistics robotics market (source: Tractica Mar, 2018)

Robots have sensors and vision that make them more efficient at supply chain management tasks such as materials handling and assembly. They're also being designed to safely work alongside humans, not necessarily in place of humans. Robot automation helps companies lower fulfillment times and costs. In a recent MHI and Deloitte survey cited by the Wall Street Journal, 35 percent of respondents have already adopted robotics into their supply chains. The same article claims, "Amazon.com Inc., for example, designs new fulfillment centers with robotics incorporated in the design.[27]"
About $35 \%$ of respondents said they'd already adopted robotics into their supply chains, and that is set to grow to $74 \%$ in the next six to 10 years, the report said

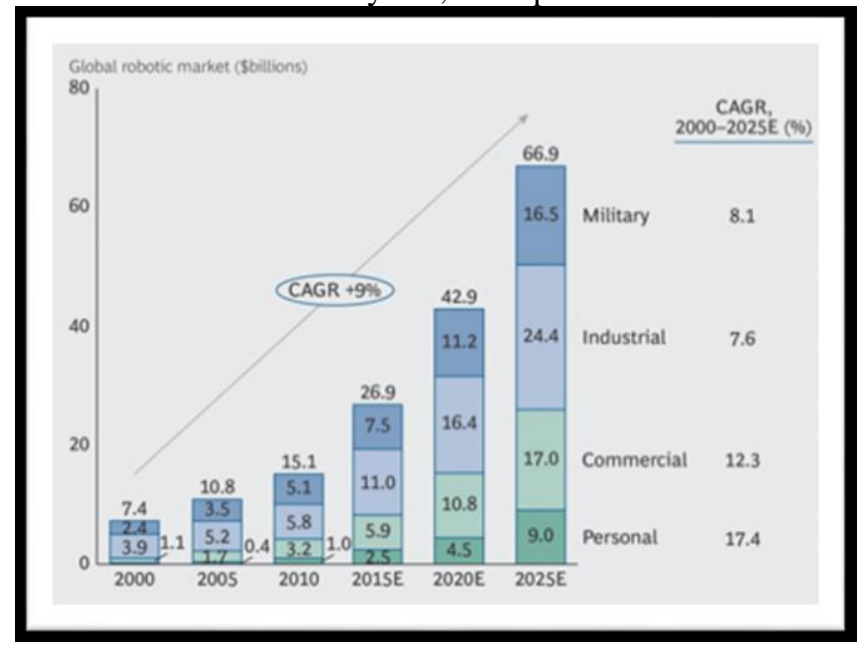

Fig. 7: Global Robot Market (Source: Boston Consulting Group, 2018)

The survey also found that a majority of respondents now plan to spend more than $\$ 1$ million on emerging technologies in the next two years, with $12 \%$ saying they will spend more than $\$ 10$ million and 3\% expecting to spend more than $\$ 100$ million. In a separate survey of managers at freight forwarders by shipping software company Freightos Ltd., 68\% said warehouse robotics would profoundly impact their industry. But only $49 \%$ saw 3D printers as having a major impact, and only $32 \%$ saw drones and self-driving trucks having significant effect and $8 \%$ pointed to augmented reality[28].

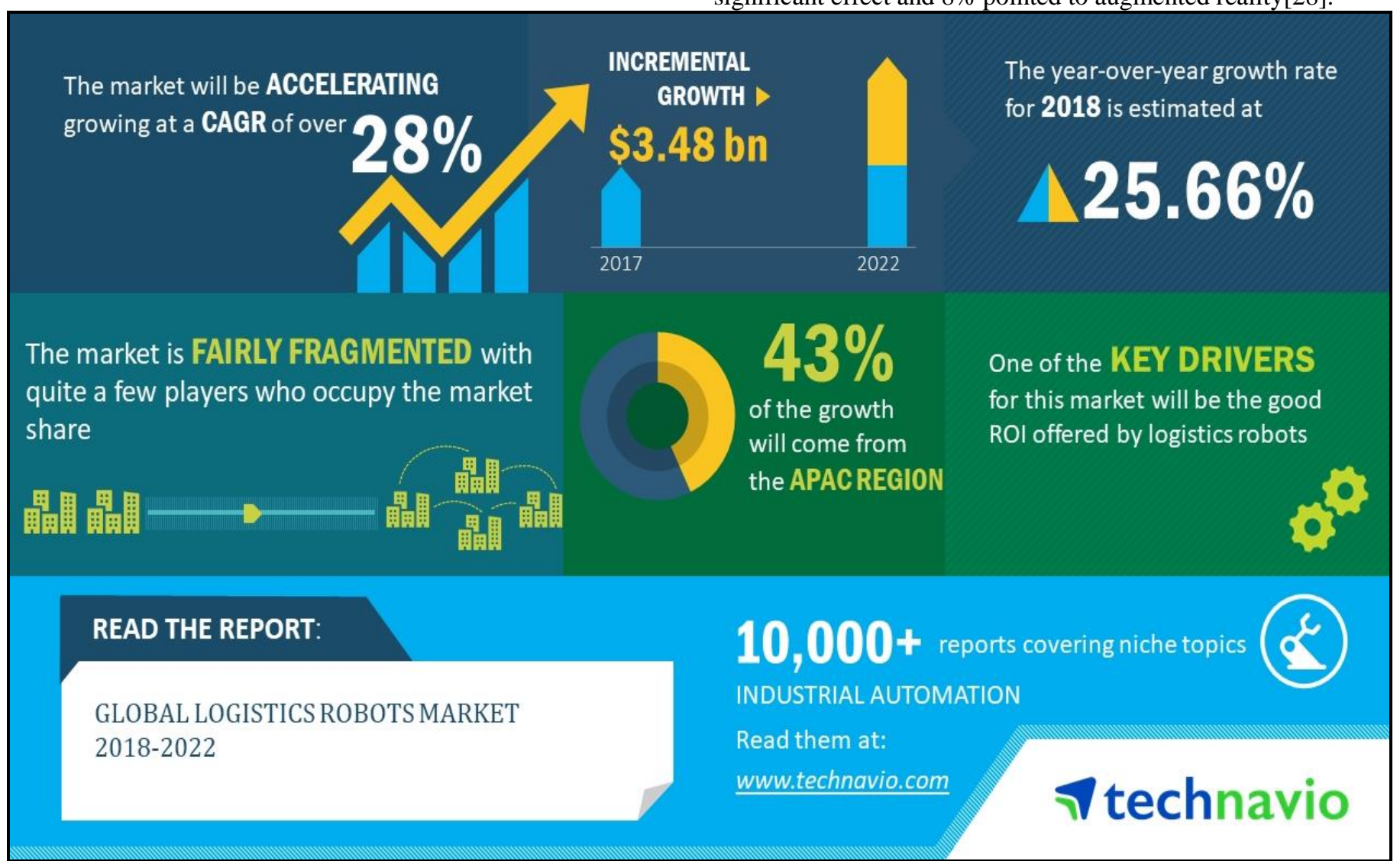

Figure 8: Global Logistics Robots Market 2018-2022, Source: BusinessWire (from Sep 2018) 


\section{CONCLUSIONS}

This work shows the high potential of Robotics for the manufacturing and machine tool industry. These use cases were analyzed using a cluster analysis and evaluated based on criteria for a beneficial application of robotics. This paper focused on Robotics in the manufacturing industry and discloses potentials and challenges. Future research opportunities lie in a deeper analysis of the business processes in the manufacturing industry to further exploit the advantages of Robotics.

Robotics has the potential to transform the supply chain and disrupt the way we retail, transport and warehouse the goods. For a successful implementation of RPA in Supply Chain, four elements need to be addressed -

- Bots for product movement through the facility

- Sensors to collect data about product quality

- Cognitive learning software systems

- Artificial Intelligence implementation to make the process lucid and flexible

Putting these pieces together is an understandable challenge but strategizing and planning each part of the implementation process \& integrating a transformation mindset into everyone in the organization would help to set the tone for change. If looking to partner with a digital transformation facilitator organization, enterprises need to take an end-to-end approach with RPA in Supply Chain implementation to achieve full benefits and realize the anticipated ROI[24].

Moreover, one-size-fits-all is no model for digital. What organizations need is an IT partner who can tailor RPA implementation services for their needs, keeping into account the present state of affairs and the end goals. Robotic Process Automation in comparison to Traditional Automation, not only substitutes labor but revamps everything an organization was built upon. New issues may arise in the service delivery process, and entire operations may get a rework, all for better productivity and efficiency at the end of the day [24]

\section{CITATIONS}

[1] Wikipedia, "Wikipedia entry on Robot," 15 Dec 2017. [Online]. Available: https://en.wikipedia.org/wiki/Robot. [Accessed 15 Nov 2018].

[2] H. T. Casey, "You'll Be Surprised How Many Robots Now Clean Our Homes," Tom's Guide, 07 Nov 2016. [Online]. Available: https://www.tomsguide.com/us/roomba-vacuums-how-popular,news23793.html. [Accessed 17 Nov 2018].

[3] L. Rouhiainen, 101 Things you must know today about our Future, 2018

[4] I. F. o. Robotics, "World Robotics Report 2016," 29 Sep 2016. [Online]. Available: https://ifr.org/ifr-press-releases/news/worldrobotics-report-2016. [Accessed 19 Dec 2018]

[5] SoftBank Robotics, "Who is Pepper?," [Online]. Available: https://www.ald.softbankrobotics.com/en/robots/pepper. [Accessed 07 Jan 2019].

[6] M. Mikael-Debass, "South Korea Has the Most Robot Workers per Human Employee in the World," Vice News, 24 May 2017. [Online]. Available: https://news.vice.com/story/south-korea-has-the-mostrobot-workers-per-human-employee-in-the-world. [Accessed 27 Nov 2018]

[7] M. Sayer, "Which Country Will Win the Robot War?", Future of Everything," Dec 2016. [Online]. Available: http://www.futureofeverything.io/2017/01/17/countries-leading-theworld-in-industrial-robotics. [Accessed 23 Nov 2018].
[8] E. Huen, "The World's First Home Robotic Chef Can Cook Over 100 Meals Lifestyle," Forbes, 31 Oct 2016. [Online]. Available: https://www.forbes.com/sites/eustaciahuen/2016/10/31/the-worldsfirst-home-robotic-chef-can-cook-over-100-meals/\#5c2423b77228 [Accessed 22 Feb 2019].

[9] iRobot, "History - iRobot," iRobot, [Online]. Available: http://www.irobot.com/About-iRobot/CompanyInformation/History.aspx. [Accessed 01 Dec 2018]

[10] Robotnews, "Dressman - The Ironing Robot," 02 Apr 2007. [Online] Available: https://robotnews.wordpress.com/2007/04/02/dressmanthe-ironing-robot. [Accessed 31 Jan 2018].

[11] Kickstarter, "Tertill: The solar powered weeding robot for home gardens," $2018 . \quad$ [Online]. Available: https://www.kickstarter.com/projects/rorymackean/tertill-the-solarpowered-weeding-robot-for-home-g. [Accessed 03 Feb 2019].

[12] Kuri, "A real Live Robot," 2018. [Online]. Available: https://www.heykuri.com

[13] J. Jones, "Roomba Inventor Joe Jones: Why I Think Home Robot Will Become Invisible," IEEE Spectrum, 10 Jul 2017. [Online] Available: https://spectrum.iee.org/automaton/robotics/homerobots/why-i-think-home-robots-will-become-invisible. [Accessed 21 Dec 2018].

[14] A. Glaser, "Boston Dynamics has been using its robot 'dog' to deliver packages in Boston," Recode, 25 Apr 2017. [Online]. Available: https://www.recode.net/2017/4/25/15422130/boston- dynamics-robotdog-deliver-packages-boston-ted. [Accessed 21 Dec 2018].

[15] J. Mannes, "Boston Dynamics' Handle robot dominates parkour on wheels in new footage," Techcrunch, 27 Feb 2017. [Online].Available: https://techcrunch.com/2017/02/27/bostondynamics-handle-robot-dominates-parkour-on-wheels-in-newfootage. [Accessed $27 \mathrm{Feb} 2017$ ].

[16] M. Simon, "Boston Dynamics' New Rolling, Leaping Robot Is an Evolutionary Marvel," Wired, 03 Jan 2017. [Online]. Available: https://www.wired.com/2017/03/boston-dynamics-new-rolling leaping-robot-evolutionary-marvel/. [Accessed 19 Dev 2018].

[17] B. Dynamics, "Spot - Takes a Kicking and Keeps on Ticking," 2017. [Online]. Available: https://www.bostondynamics.com/spot [Accessed 21 Dec 2018].

[18] B. Dynamics, "SpotMini, Good Things Come in Small Packages," 2017. [Online]. Available: https://www.bostondynamics.com/spotmini. [Accessed 04 Nov 2018].

[19] The Business Times, "SoftBank's Son explains how all those deals fit together," 21 Jul $2017 . \quad$ [Online]. Available: http://www.businesstimes.com.sg/technology/softbanks-son-explainshow-all-those-deals-fit-together. [Accessed 03 Feb 2019].

[20] D. Galeon, "Boston Dynamics CEO Believes Robotics Will Become "Bigger Than the Internet," Futurism, 15 Nov 2017. [Online] Available: https://futurism.com/boston-dynamics-ceo-believesrobotics-bigger-internet. [Accessed 25 Jan 2019].

[21] SophiaBot, "Sophia," 2017. [Online]. Available: http://sophiabot.com/about-me. [Accessed 23 Dec 2018]

[22] J. Vincent, "Pretending to give a robot citizenship helps no one," The Verge, 30 Oct 2017. [Online]. Available: https://www.theverge.com/2017/10/30/16552006/robot-rightscitizenship-saudi-arabia-sophia. [Accessed 23 Feb 2019].

[23] i-Scoop, "Robots and cobots in logistics - the next stage of growth Industry 4.0," [Online]. Available: https://www.i-scoop.eu/robotscobots-logistics-4-0/. [Accessed 21 Dec 2018].

[24] M. TECHLABS, "RPA IN SUPPLY CHAIN - THE KEY TO SCM SUCCESS," [Online]. Available: https://www.marutitech.com/rpa-insupply-chain/. [Accessed 11 Dec 2018].

[25] "The Internet of Things: How "Process Robots" Are Transforming Supply Chains," SupplyChain24x7, 08 Oct 2014. [Online]. Available: http://www.supplychain247.com/article/the_internet_of_things_how_ process_robots_are_transforming_supply_chains/One_Network_Ente rprises. [Accessed 21 Nov 208].

[26] S. Shah, "What Robot means for the Supply Chain," Redwood Software, 13 Oct 2017. [Online]. Available: https://www.redwood.com/article/what-robotics-means-for-thesupply-chain/. [Accessed 19 Dec 2018]

[27] J. Steding, "Supply Chain Management Trends in Industry 4.0," [Online]. Available: https://www.soneticscorp.com/4-supply-chainmanagement-trends/. [Accessed 08 Dec 2018]. 
[28] L. Chao, "The Wall Street Journal," 06 Apr 2016. [Online]. Available: https://www.wsj.com/articles/robots-gain-traction-withsupply-chain-managers-1459936836. [Accessed 03 Nov 2018].

[29] "Robotic Process Automation (RPA) Tutorial: What is, Tools \& Example," Guru99, [Online]. Available: https://www.guru99.com/robotic-process-automation-tutorial.html\#5. [Accessed 17 Dec 2018].
[30] Virbahu Nandishwar Jain, 2019, Artificial Intelligence (AI) for Supply Chain Industries and the Future It Holds!, INTERNATIONAL JOURNAL OF ENGINEERING RESEARCH \& TECHNOLOGY (IJERT) Volume 08, Issue 03 (March - 2019) [Online]. Available: https://www.ijert.org/research/artificialintelligence-ai-for-supply-chain-industries-and-the-future-it-holdsIJERTV8IS030041.pdf.. 